\title{
Response by Specialist and Generalist Natural Enemies to Agroecosystem Diversification: A Selective Review
}

\author{
WILLIAM SHEEHAN
}

\author{
Department of Entomology, New York State Agricultural Experiment Station, \\ Cornell University, Geneva, New York 14456
}

\begin{abstract}
FORUM: Environ. Entomol. 15: 456-461 (1986)
ABSTRACT Effects of agroecosystem diversification on searching behavior and success of arthropod natural enemies are poorly understood. Crop diversification may increase generalist enemy effectiveness by increasing alternate food or prey availability, as predicted by the enemies hypothesis. But diversification may also reduce enemy searching efficiency and destabilize predator/prey interactions. Additionally, specialist enemies, often important in biological control programs, may be particularly sensitive to vegetation texture. Pest control by specialist enemies may be more effective in less diverse agroecosystems if concentration of host plants increases attraction or retention of these enemies.
\end{abstract}

Agricultural DIVERSIFICATION often leads to reduced pest populations (reviewed by Perrin \& Phillips 1978, Way 1979, Cromartie 1981, Risch et al. 1983, Altieri \& Letourneau 1984, Andow 1985), but the mechanisms involved are poorly understood. Root (1973) formulated two hypotheses to explain differences in herbivore populations in simple and diverse habitats. The resource concentration hypothesis predicts that monophagous or oligophagous herbivores are more likely to find, remain in, and build up populations in places such as monocultures where their host plants are concentrated. Polyphagous herbivores, on the other hand, are more likely to drift away from such patches into surrounding vegetation. The enemies hypothesis predicts that populations of natural enemies will be greater, and, consequently, herbivore populations lower, in diversified habitats due to the increased availability of alternate prey, nectar sources, and suitable microhabitats.

While the two hypotheses are neither comprehensive nor mutually exclusive, they have been the focus of recent experimental work in agricultural settings (Bach 1980, Risch 1981, Tukahirwa \& Coaker 1982, Andow 1983, Salick 1983). These studies provided little support for the enemies hypothesis. Furthermore, a review by Risch et al. (1983) concluded that "herbivore movement patterns are more important than the activities of natural enemies in explaining the reduction of mo. nophagous pest populations in diverse annual systems."

In this paper, I argue that one cannot rule out, on the basis of currently available information, the ability of natural enemies to limit herbivore populations in many situations. Additionally, I exam.. ine the consequences of resource concentration on natural enemies, and I propose that enemy foraging behavior and population dynamies be viewed in terms of concentration both of victims and of victim-containing vegetation (cf. Risch 1981). In particular, consideration of responses by specialist enemies to such concentration suggests alternative hypotheses and predictions about natural enemy effectiveness in agroecosystems.

Definitions. Natural enemies of insect herbivores include insect parasitoids and arthropod predators. Pathogens and predators other than arthropods, although undoubtedly of importance, are not considered here. I use victims as shorthand for prey or hosts of natural enemies. Foraging refers to the activities of both predators hunting prey for food as well as adult female parasitoids hunting hosts on which to feed or in which to oviposit. Successful foraging ultimately results in death of victims in all cases. Diets of specific natural enemies may be restricted to 1) one or several related victim species (victim specialists), or to a number of victim species that exploit either; 2) a narrow range of plant species (plant specialists); or 3) specific plant structures, such as plant stems or leaf mines (niche specialists). Generalist enemies use more species or exploit more kinds of plants or plant structures. For clarity I use the terms oligophagous and polyphagous to describe herbivore diet breadth. Diet specialization is relative and may be affected by local ecological conditions (Fox \& Morrow 1981), population density (Zwölfer 1971), or even individual experience (Arthur 1971, 1981, Vet 1983). Despite such difficulties, the concept of diet specialization is heuristic. Insect parasitoids tend on average to have narrower diets (attack fewer host species) than arthropod predators (Askew 1971, Price 1980, Vinson \& Iwantsch 1980). Consequently, my discussion of specialist enemies emphasizes parasitoids.

\section{Tests of the Hypotheses}

To test the resource concentration and enemies hypotheses, one would like to directly measure, in simple and diverse systems, pest movement and 
reproduction as well as mortality caused by natural enemies. Risch et al. (1983) examined 150 reports in the literature that describe pest abundance in both simple and diverse systems, yet they found only three studies that directly tested both of the hypotheses. Of these studies, those by Bach (1980) and Risch (1981) examined only the adult stage of herbivorous beetle species that have subterranean larval stages. Because differential mortality of larvae was not assessed, the overall role of natural enemies could not be determined. The third study mentioned (ICRISAT: see Bhatnagar and Davies [1982]) found both pest movement and natural enemies to be important in determining pest abundance patterns. Other recent studies that have examined both herbivore movement and enemycaused mortality have suffered from insufficient sampling to determine enemy activity (Andow 1983), or inadequate replication and experimental control (Tukahirwa \& Coaker 1982). In one study (Salick 1983), numbers of enemies were insignificant. However, in systems where enemies are present, studies to date do not allow for rejection of the enemies hypothesis.

\section{Importance of Interactions Between Plants and Generalist Enemies}

Consideration of enemy response both to victim concentration and to vegetation texture (Root 1975) suggests that predictions made by the enemies hypothesis are simplistic. Some factors appear to favor greater enemy abundance or effectiveness in diverse systems, but others may favor enemy success in simple systems. Most research on natural enemies has been limited to interactions between enemies and victims. Many authors believe that enemies tend to aggregate, on some scales at least, in areas of high victim density (reviewed by Hassell [1978, 1982], but see Morrison and Strong [1980]). By itself, a strong enemy aggregation response might be predicted in some situations to counteract concentration of oligophagous herbivores in simple habitats. However, a full understanding of the effects of enemies on herbivore populations, as well as of the effects of agricultural diversification on enemy/herbivore interactions, must incorporate an understanding of interactions between enemies and vegetation (Price et al. 1980).

Enemy response to vegetation factors has received less attention than enemy response to victim density and dispersion. The enemies hypothesis considers the importance of plant factors primarily through the effects of varied nectar sources and microhabitat complexity and quality in attracting and retaining those enemies that can use alternate prey species (Root 1973, Cromartie 1981, Risch 1981). These factors may indeed be important to the foraging success of many enemies, especially of generalist enemies (see reviews by Price et al. [1980], Vinson [1981], and Altieri \& Letourneau [1982]). Furthermore, these factors may lead to patterns of higher predation and parasitism in some diverse cultures (e.g., Altieri et al. [1981] and Letourneau \& Altieri [1983]). However, two arguments suggest other possible predictions: 1) plant-related factors other than those considered by the enemies hypothesis may counteract generalist enemy success in diverse habitats (see below) and 2) the enemies hypothesis as currently formulated may be less applicable to specialist than to generalist natural enemies (see Specialist Enemies).

A largely neglected interaction is that between leaf surface area and foraging success of enemies that locate prey visually or by random contact. Need \& Burbutis (1979) found that parasitism rates by Trichogramma nubilale Eartle and Davis varied inversely with leaf area of corn plants. Similarly, O'Neil (1984) demonstrated that predation rates on Anticarsia gemmatalis Hübner larvae are directly correlated with changes in host plant (soybean) leaf area. Apparently, as leaf surface area increases during the growing season, visually or tactilely searching enemies must search more area to find the same number of prey. Leaf surface area per unit soil area tends to be greater in diverse than in simple systems due to planting practices and to the closer spacing often possible with plants of different architecture (Andow 1985). Visually or tactilely searching enemies may therefore be less effective in reducing herbivore populations in dense, diverse systems than in sparser, simple systems, other factors being equal. Consistent with this hypothesis, Risch et al. (1982) found that foraging rates of Coleomeqilla maculata (DeGeer) in laboratory cages were significantly reduced by increasing the density (but not diversity) of plants on which they foraged. The authors suggested that high plant density reduced enemy searching effectiveness and resulted in higher herbivore loads in the high density treatments.

Spatial dispersion of patches of plants containing potential victims in diverse agroecosystems, in conjunction with victim distribution, may exert strong effects on enemy/victim dynamics. Huffaker (1958), in a classic laboratory study, showed that the ability of predatory mites to coexist with their herbivorous mite prey was dependent on environmental complexity and dispersal rates of predator and prey. Until recently, spatial heterogeneity has been incorporated into models of enemy/victim dynamics only to the extent that internally homogenous patches differ in prey density. Kaiser (1983) examined the effects of patch size, shape, and internal structure in laboratory experiments and found that these factors affected both encounter and predation rates of a mite predator that apparently searches randomly. In field experiments Kareiva (1983b) found that the placement of artificial barriers in strips of goldenrod altered the relative mobilities of a coccinelid beetle and its aphid prey and led to aphid outbreaks. Interestingly, patchiness at the scale studied by Kareiva 
destabilized the predator/prey system, while in Huffaker's (1958) laboratory study patchiness was necessary to prevent prey extinction.

\section{Specialist Enemies}

The distinction between oligophagous and polyphagous herbivores is central to the resource concentration hypothesis: oligophagous herbivores are predicted to respond more strongly than polyphagous herbivores to resource concentration (Root 1973, Kareiva 1983a). A similar distinction has not been made for enemies, but in fact it is generalist enemies that are usually mentioned or implied in discussions of the enemies hypothesis. A primary tenet of the enemies hypothesis, as it has been developed by Pimentel (1961), Root (1973), Risch (1981), and Andow (1985), is that enemies should be more abundant and effective in diverse systems because of the greater availability of alternative prey, implying that effective enemies are generalists. Certainly maintenance of enemy populations on alternative prey is a characteristic that increases the effectiveness of many generalist enemies, especially in annual agroecosystems (Ehler \& Miller 1978). However, specialist enemies may often be more effective than generalists in controlling herbivore populations, just as oligophagous herbivores are often more effective in exploiting host plants, and comprise the major portion of the herbivore load in many systems (Root 1973, Kogan 1981). The number of successes (Beddington et al. 1978, Waage \& Hassell 1982) and the rates of success (Hall et al. 1980) of biological control introductions using specialist enemies indicate the widespread importance of specialist enemies in natural and agricultural systems. Considering their importance, it is of considerable interest to determine if specialist enemies respond to vegetation texture differently from generalist enemies, just as oligophagous herbivores often respond differently from generalist herbivores. Except for passing mention by some authors (e.g., by Root [1973], Perrin \& Phillips [1978]), discussion of agroecosystem diversification has not considered the potential contribution of specialist enemies.

The results of three field studies are consistent with the hypothesis that specialist enemies, particularly parasitoids, may be equally or more abundant or effective in simple than in diverse systems. P. Gross (personal communication) controlled for host density and measured parasitism of Nantucket pine tip moth larvae, Rhyacionia frustrana. (Comstock), in experimental weedy and mowed stands. Preliminary results suggested that parasitism by two generalist wasp parasitoids was higher in weedy stands, while parasitism by a tachinid. specialist, Lixophaga mediocris Aldrich, was not: significantly influenced by the presence of weeds. Smith (1976) compared the rates of parasitism of cabbage aphids by the crucifer-specialist parasit- oid Diaeretiella rapae (M'Intosh) on weedy and tilled Brussels sprout plots. During 1 month when aphid densities were (coincidentally) equal in both treatments, she found 4-fold higher parasitism in the tilled monoculture plots. Finally, Richards (1940) recorded parasitism of Artogeia (=Pieris) rapae (L.) on potted cabbage plants placed in cabbage plots and old fields. He reared the specialist parasitoid Apanteles rubecula Marshall only from host larvae from cabbage monoculture plots, whereas he reared equal numbers of the generalist parasitoid Phryxe vulgaris (Fallén) from larvae from cabbage in uniform stands and in diverse vegetation.

Possibly contrary to the above results, D. Letourneau (personal communication) found that larval Diaphania hyalinata (L.) were attacked more often by parasitoids in squash/bean/corn triculture than in squash monoculture, despite higher host densities in monoculture plots. Assessment of parasitoid specialization in this case is hindered, however, by the fact that only one species (a generalist) was identified to species. Unfortunately, few experiments have been designed to determine enemy response to habitat factors, independent of enemy response to host density. Host density must be controlled in such experiments before the importance of particular habitat variables on enemy effectiveness can be assessed.

\section{Mechanisms of Specialist \\ Enemy Concentration}

Vegetation texture may influence enemy searching behavior and population dynamics in ways analogous to its influence on herbivores (Vinson 1981, Kareiva 1983a, Stanton 1983). At least three general mechanisms can lead to increased populations of natural enemies in particular habitats: 1) high rates of immigration to patches of host or host plant concentration; 2) low rates of emigration; and 3) high survival and reproduction of successful immigrants within such patches. These mechanisms may operate in many situations to concentrate specialist enemies in patches of higher resource (host and host plant) concentration, and therefore in simple rather than in diverse habitats.

Patch Immigration. Plants provide visual, olfactory, and tactile stimuli that may be used as long-range attractants or as short-range arrestants by enemies in habitat or patch location (reviewed by Vinson [1976, 1984]; see Drost et al. 1986). However, evidence for distant (>10 m) olfactory orientation to plants is controversial for herbivores (Finch \& Skinner 1982), and is entirely lacking for enemies. Specialist herbivores appear to use more specific chemical and visual cues than generalists in orienting to host plants (Städler 1977, Prokopy \& Owens 1978); this may be true for enemies as well (Vinson 1976). Furthermore, when specific plant cues are used by insects to locate plant 
patches, the presence of other plants in close association with these plants may disrupt orientation to the patch. Such disruption may be due to the masking of attractant or arrestment cues, to the presence of repellant cues, or to a combination of these (Tahvanainen \& Root 1972, Dethier 1982). Olfactory disruption has been demonstrated more often for herbivores, but has been suggested for enemies as well (Monteith 1960, Cromartie 1981). If diverse vegetation has the effect of obscuring victim-containing plants, it is possible that specialist enemies will be more affected than generalists. Consequently, specialist enemies may colonize simple agroecosystems more readily than diverse systems.

Patch Emigration. The tendency of enemies to leave patches may also be influenced by plant population factors. Recognition of patch boundaries has been suggested to be critical for retaining certain herbivore species (Stanton 1983, Kareiva 1985), and Waage (1979) found that edge recognition in patches defined by host kairomones was a key determinant of patch time for the parasitoid Nemeritis canescens (Gravenhorst) attacking a grain moth. Although evidence is lacking, it is possible that enemy recognition of plant-defined patch boundaries (probably coupled with encounter rate with potential victims) may similarly affect patch time for some species, especially for specialist enemies that are adapted to search in dense, low-diversity stands. If so, then the alteration or obscuring of patch boundaries that may accompany agroecosystem diversification may adversely affect retention of those enemy species.

Within-patch Success. The presence in diverse systems of more nectar sources than in simple systems may indeed favor within-patch success of many enemies, as predicted by the enemies hypothesis. However, host feeding is often essential for adult parasitoids (Bartlett 1964, Sandlan 1979) and may account for a significant proportion (Van Driesche 1983) or even a majority (DeBach 1943) of parasite-inflicted mortality for some host species. For both specialist and generalist parasitoids, tenure time in patches may depend in some cases on availability of acceptable prey for feeding rather than on availability of nectar. The relative importance of nectar feeding versus host feeding to adult parasitoid reproductive success, and their effects on foraging behavior, deserves further study.

Scale. The question of spatial scale may also be relevant to the assessment of effects of cultural practices on enemy searching behavior. Concentration of host plants of herbivores may be effective in attracting or retaining enemies at intermediate scales, while less effective or ineffective at the scale of hectares. Enemies adapted to searching diverse natural habitats may at some point become habituated to superabundant plant cues and may tend to leave these areas after a limited time searching. However, evidence is insufficient.

\section{Conclusions}

An important result of experiments and analyses inspired by the resource concentration hypothesis (Root 1973) is that differential abundance of herbivores in simple and diverse agroecosystems may not in many cases be due to enemy-inflicted mortality. However, enemies clearly do inflict significant mortality on many herbivore pests. The hypothesis that natural enemies should be more abundant or effective where more alternative food sources are available (enemies hypothesis) is simplistic in several respects. Victim location by generalist enemies may be hindered by increased plant density or patchiness in diverse agricultural systems. More importantly, specialist enemies should not necessarily respond to habitat diversification in the same way as generalists. Factors that increase immigration to and decrease emigration from host plant areas by specialist enemies (e.g., large patch size, close plant spacing, the presence of specific chemical or visual stimuli, and lower chemical or structural diversity of associated vegetation) may cause those enemies to remain longer and hunt more effectively in simple than in diverse agroecosystems, at least in those that are not too extensive.

Several questions are raised by these speculations. How important is mortality caused by specialist versus generalist enemies in agroecosystems? Can behavioral modification (learning or switching) cause generalist enemies to function as specialists? Does the tendency of some enemies to limit search to specific plants or plant structures influence enemy foraging efficiency in diversified agroecosystems? Is diet specialization a useful concept at all? More generally, answers are needed to the following questions: How important is enemycaused mortality relative to herbivore movement in influencing pest population response to agricultural diversification? Does the ecology of enemy/ herbivore interactions differ fundamentally between agroecosystems and less disturbed or natural systems? Can the results of small-plot experiments be meaningfully extrapolated to large-scale agriculture? Finally, can useful generalizations be made about natural enemy response to agroecosystem diversification, or must each case be considered on an individual basis, as is suggested by Nordlund et al. (1984)? Clearly, more extensive and careful experimentation is needed to detect effects of agroecosystem diversification on both pest abundance and on pest control by natural enemies. Herbivore density must be controlled in these experiments. Observation and, preferably, experimentation in natural systems can also help elucidate ways in which agricultural practices can be altered to enhance enemy activity. Ultimately, perhaps, cultural practices can be manipulated to advantage with better knowledge of their effects on key enemy/victim combinations. 


\section{Acknowledgment}

I am grateful to the following people for their helpful comments on earlier drafts of this manuscript: $D$. A Andow, M. L. Cain, J. L. Dickinson, G. C. Eickwort, P. P. Feeny, P. Gross, P. Kareiva, D. K. Letourneau, J. P. Nyrop, M. R. Richter, S. J. Risch, R. B. Root, A. M. Shelton, K. Stoner, and an anonymous reviewer.

\section{References Cited}

Altieri, M. A. \& D. K. Letourneau. 1982 . Vegetation management and biological control in agroecosysterns. Crop Prot. 1: 405-430.

1984. Vegetation diversity and insect pest outbreaks. CRC Crit. Rev. Plant. Sci. 2: 131-169.

Altieri, M. A., W. J. Lewis, D. A. Nordlund, R. C. Gueldner \& J. W. Todd. 1981. Chemical interactions between plants and Trichogramma wasps in Georgia soybean fields. Prot. Ecol. 3: 259-263.

Andow, D. A. 1983. Plant diversity and insect populations: interactions among beans, weeds and insects. Ph.D. dissertation, Cornell Univ., Ithaca, N.Y.

1985. Plant diversification and insect population control in agroecosystems. In D. Pimentel [ed.], Some aspects of integrated pest management. Dep. of Entomology, Cornell Univ., Ithaca, N.Y.

Arthur, A. P. 1971. Associative learning by Nemeritis canescens (Hymenoptera: Ichneumonidae). Can. Entomol. 105: 145-156.

1981. Host acceptance by parasitoids, pp. 97-120. In D. A. Nordlund, R. L. Jones, and W. J. Lewis [eds.], Semiochemicals: their role in pest control. Wiley, New York.

Askew, R. R. 1971. Parasitic insects. Elsevier, New York.

Bach, C. E. 1980. Effects of plant density and diversity on the population dynamics of a specialist herbivore, the striped cucumber beetle, Acalymma vittata (Fab.). Ecology 61: 1515-1530.

Bartlett, B. R. 1964. Patterns in the host-feeding habit of adult parasitic Hymenoptera. Ann. Entomol. Soc. Am. 577: 344-350.

Beddington, J. R., C. A. Free \& J. H. Lawton. 1978. Modelling biological control: on the characteristics of successful natural enemies. Nature (London) 273: 513-519.

Bhatnagar, V. S. \& J. C. Davies. 1982 . Pest manage-ment in intercropping subsistence farming, pp. 249257. In R. W. Wiley [ed.], Proceedings, Internationa] workshop on intercropping. International Crops Research Institute for the Semi-Arid Tropics, Patancheru, India.

Cromartie, W. J. 1981. The environmental control of insects using crop diversity, pp. 223-251. In D. Pimentel [ed.], Handbook of pest management in agriculture, vol. 3. CRC, Boca Raton, Fla.

DeBach, $P$. 1943. The importance of host-feeding by adult parasites in the reduction of host populations. J. Econ. Entomol. 36: 647.

Dethier, V. G. 1982. Mechanism of host-plant recognition. Entomol. Exp. Appl. 31: 49-56.

Drost, Y. C., W. J. Lewis, P. O. Zanen \& M. A. Keller. 1986. Beneficial arthropod behavior mediated by airborne semiochemicals. I. Flight behavior and influence of preflight handling of Microplitis croceipes (Cresson). J. Chem. Ecol. (in press).

Ehler, L. E. \& S. C. Miller. 1978. Biological control in temporary agroecosystems. Entomophaga 23: 207212.

Finch, S. \& G. Skinner. 1982. Upwind flight by the cabbage root fly, Delia radicum. Physiol. Entomol. 7: 387-399.

Fox, L. R. \& P. A. Morrow. 1981. Specialization: species property or local phenomenon? Science 211 : 887-893.

Hall, R. W., L. E. Ehler \& B. Bisabri-Ershadi. 1980. Rate of success in classical biological control of arthropods. Bull. Entomol. Soc. Am. 26: 111-114.

Hassell, M. P. 1978. The dynamics of arthropod predator-prey systems. Princeton Univ., Princeton, N.J.

1982. Patterns of parasitism by insect parasitoids in patchy environments. Ecol. Entomol. 7: 365-377.

Huffaker, C. B. 1958. Experimental studies on predation: dispersion factors and predator-prey oscillations. Hilgardia 27: 343-383.

Kaiser, H. 1983. Small scale spatial heterogeneity influences predation success in an unexpected way: model experiments on the functional response of predatory mites (Acarina). Oecologia (Berlin) 56: 249256.

Kareiva, P. 1983a. The influence of vegetation texture on herbivore populations: resource concentration and herbivore movement, pp. 259-289. In R. F. Denno \& M. S. McClure [eds.], Variable plants and herbivores in natural and managed systems. Academic, New York.

1983b. Predator-prey dynamics in spatially structured populations: manipulating dispersal in a coccinellid-aphid interaction, pp. 368-389. In S. A. Levin \& G. Hallam [eds.], Mathematical ecology. Lecture Notes in Biomathematics, No. 54. Springer, New York.

1985. Finding and losing host plants by Phylotreta: patch size and surrounding habitat. Ecology 66: 18091816.

Kogan, M. 1981. Dynamics of insect adaptations to soybeans: impact of integrated pest management. Environ. Entomol. 10: 363-371.

Letourneau, D. K. \& M. A. Altieri. 1983. Abundance patterns of a predator, Orius tristicolor (Hemiptera: Anthocoridae), and its prey, Frankliniella occidentalis (Thysanoptera: Thripidae): habitat attraction in polycultures versus monocultures. Environ. Entomol. 12: 1464-1469.

Monteith, L. G. 1960 . Influence of plants other than the food plants of their host on host-finding by tachinid parasites. Can. Entomol. 92: 641-652.

Morrison, G. \& D. R. Strong. 1980. Spatial variation in host density and the intensity of parasitism: some empirical examples. Environ. Entomol. 9: 149-152.

Need, J. T. \& P. P. Burbutis. 1979. Searching efficiency of Trichogramma nubilale. Environ. Entomol. 8: 224-227.

Nordlund, D. A., R. B. Chalfant \& W. J. Lewis. 1984. Arthropod populations, yield and damage in monocultures and polycultures of corn, beans and tomatoes. Agric. Ecosyst. Environ. 11: 353-367.

O'Neil, R. J. 1984. Measurement and analysis of predation on Anticarsia gemmatalis Hubner by a complex of arthropod predators. Ph.D. dissertation, Univ. of Florida, Gainesville.

Perrin, R. M. \& M. L. Phillips. 1978. Some effects of mixed cropping on the population dynamics of insect pests. Entomol. Exp. Appl. 24: 585-593. 
Pimentel, D. 1961. Species diversity and insect population outbreaks. Ann. Entomol. Soc. Am. 54: 7686.

Price, P. W. 1980. Evolutionary biology of parasites. Princeton Univ., Princeton, N.J.

Price, P. W., C. E. Bouton, P. Gross, B. A. McPheron, J. N. Thompson \& A. E. Weis. 1980 . Interactions among three trophic levels. Annu. Rev. Ecol. Syst. 11: 41-65.

Prokopy, R. J. \& E. D. Owens. 1978. Visual generalist and visual specialist phytophagous insects: host selection behavior and application to management. Entomol. Exp. Appl. 24: 409-420.

Richards, 0 . W. 1940. The biology of the small white butterly (Pieris rapae), with special reference to the factors controlling its abundance. J. Anim. Ecol. 9: 243-288.

Risch, S. J. 1981. Insect herbivore abundance in tropical monocultures and polycultures: an experimental test of two hypotheses. Ecology 62: 13251340.

Risch, S. J., R. Wrubel \& D. A. Andow, 1982. Foraging by a predaceous beetle, Coleomegilla maculata (Coleoptera: Coccinellidae), in a polyculture: effects of plant density and diversity. Environ. Entomol. 11: 949-950.

Hisch, S. J., D. Andow \& M. A. Altieri. 1983. Agroecosystem diversity and pest control: data, tentative conclusions, and new research directions. Environ. Entomol. 12: 625-629.

Root, R. B. 1973. Organization of a plant-arthropod association in simple and diverse habitats: the fauna of collards (Brassica oleracea). Ecol. Monogr. 43: 94125.

1975. Some consequences of ecosystem texture, pp. 83-91. In S. A. Levin [ed.], Ecosystem analysis and prediction. Society for Industrial and Applied Mathematics, Philadelphia.

Salick, J. 1983. Agroecology of the cassava lacebug. Ph.D. dissertation, Cornell Univ., Ithaca, N.Y.

Sandlan, K. P. 1979. Host-feeding and its effects on the physiology and behaviour of the ichneumonid parasitoid, Coccygomimus turionellae. Physiol. Entomol. 4: 383-392.

Smith, J. G. 1976. Influence of crop background on natural enemies of aphids on Brussels sprouts. Ann. Appl. Biol. 83: 15-29.

Städler, E. 1977. Sensory aspects of insect-plant interactions, pp. 228-248. In Proceedings, 15th International Congress of Entomology, Washington, D.C., 1976.

Stanton, M. L. 1983. Spatial patterns in the plant community and their effects upon insect search, pp.
125-157. In S. Ahmad [ed.], Herbivorous insects: host seeking behavior and mechanisms. Academic, New York.

Tahvanainen, J. \& R. B. Root. 1972. The influence of vegetational diversity on the population ecology of a specialized herbivore, Phyllotreta cruciferae (Coleoptera: Chrysomelidae). Oecologia (Berlin) 10: 321-346.

Tukahirwa, E. M. \& T. H. Coaker. 1982. Effect of mixed cropping on some insect pests of brassicas: reduced Brevicoryne brassicae infestations and influences on epigeal predators and the disturbance of oviposition behavior in Delia brassicae. Entomol. Exp. Appl. 32: 129-140.

Van Driesche, R. 1983. Meaning of percent parasitism in some studies of insect parasitoids. Environ. Entomol. 12: 1611-1622.

Vet, L. E. 1983. Host-habitat location through olfactory cues by Leptopilina clavipes (Hartig) (Hym. Eucoilidae), a parasitoid of fungivorous Drosophila: the influence of conditioning. Neth. J. Zool. 33: 225248.

Vinson, S. B. 1976. Host selection by insect parasitoids. Annu. Rev. Entomol. 21: 109-133.

1981. Habitat location, pp. 51-77. In D. A. Nordlund, R. L. Jones \& W. J. Lewis [eds.], Semiochemicals: their role in pest control. Wiley, New York.

1984. Parasitoid-host relationship, pp. 205-233. In W. J. Bell \& R. T. Cardé [eds.], Chemical ecology of insects. Sinauer, Sunderland, Mass.

Vinson, S. B. \& G. F. Iwantsch. 1980. Host regulation by insect parasitoids. Q. Rev. Biol. 55: 143-165.

Waage, J. K. 1979. Foraging for patchily distributed hosts by the parasitoid Nemeritis canescens. J. Anim. Ecol. 48: 353-371.

Waage, J. K. \& M. P. Hassell. 1982 . Parasitoids as biological control agents-a fundamental approach. Parasitology 84: 241-268.

Way, M. J. 1979. Significance of diversity in agroecosystems, pp. 9-12. In Proceedings, Plenary Session Symposium, IX International Congress on Plant Protection, Washington, D.C.

Zwölfer, H. 1971. The structure and effect of parasite complexes attacking phytophagous host insects, pp. 405-418. In P. J. Den Boer \& G. R. Gradwell [eds.], Dynamics of populations. In Proceedings, Advanced Study Institute on Dynamics of Numbers in Populations (Oosterbeck, 1970). PUDOC, Wageningen, The Netherlands.

Received for publication 15 July 1985; accepted 3 March 1986. 